\title{
History of Brachytherapy
}

\section{(D) Gönül KEMIKLER}

Department of Medical Physics, İstanbul University Institute of Oncology, İstanbul-Turkey

\begin{abstract}
SUMMARY
The origin of brachytherapy is directly related to the discovery of radioactivity by Becquerel in 1896, which led to Marie and Pierre Curie discovering radium in 1898. The first successful radium brachytherapy was the skin irradiation of two patients with basal cell carcinoma in St. Petersburg in 1903. The surface mold and plaque treatments were followed by intracavitary techniques for cervical and endometrial cancer. A few years later, an interstitial radium brachytherapy technique was developed, and most body areas were treated with radium brachytherapy. In the 1950s, radium was replaced by artificial cobalt-60 and cesium-137. In the 1960s, iridium-192 was the most commonly used source of brachytherapy. During this time period, remote afterloading devices were developed, and improvements in imaging techniques and computer technology were adapted to brachytherapy. The evolution of brachytherapy has continued over the years, but many of the techniques have remained unchanged. The limited use of brachytherapy compared to conformal external radiotherapy may be due to its invasive approach, operative risk, technical difficulty, and long learning curve. Today with the development of imaging techniques and dose planning, individual treatment planning has become possible. The success of brachytherapy has increased with extensive technological advances, accurate three-dimensional dose distributions in the patient, and optimization of treatment planning. In this article, the history of brachytherapy will be briefly reviewed.

Keywords: Brachytherapy history; dosimetry systems; iridium; radioactivity; radium.

${ }^{\star}$ Emeritus professor

Copyright $\odot$ 2019, Turkish Society for Radiation Oncology
\end{abstract}

Brachytherapy is a treatment modality as old as the history of radiotherapy in cancer treatment.[1] The word brachytherapy is derived from the word brachy, which means "short" in Greek. In brachytherapy, closed radioactive sources are placed in or near the tumor. In many ways, brachytherapy can be considered the final form of conformal radiation therapy because it is unique in its ability to deliver high amounts of radiation to the tumor, while minimizing radiation exposure to normal structures. Brachytherapy has a long history in the treatment of neoplastic disease. The history of brachytherapy began in 1896 in Paris. Following the discovery of X-rays by Wilhelm Konrad von Röentgen in 1895, French physicist A. Henri Becquerel (Fig. 1) discovered that uranium spontaneously emitted rays similar to Roentgen rays.

He identified natural radioactivity in his photographic album in contact with uranium crystals in 1896. In 1898, Marie Sklodowska Curie and her husband, Pierre Curie (Fig. 2), first identified polonium and radium, two radioactive elements present in minute quantities in uranium ore.

Shortly after the discovery of radioactivity, Pierre Curie recommended the use of radioactive isotopes for cancer treatment. At the same time, Alexander Graham Bell made a similar proposal in the United States. Thus, these rays were used in medicine in the early 1900 s. 

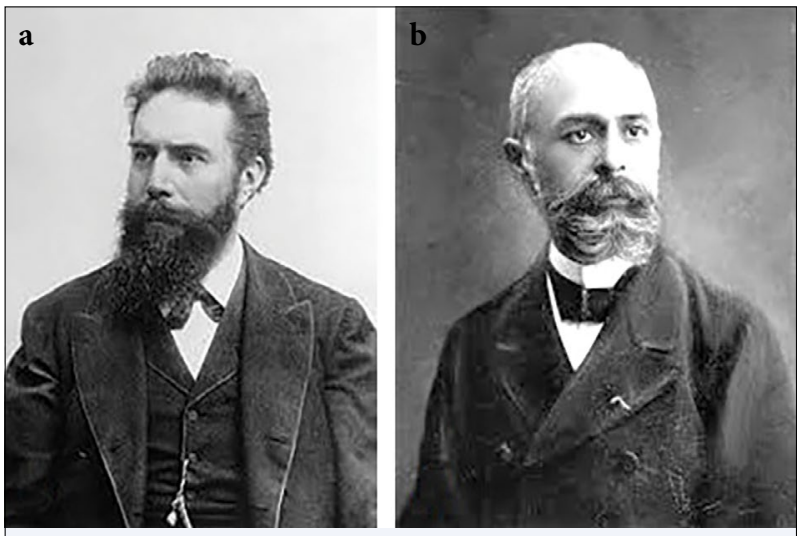

Fig. 1. (a) Wilhelm K Röentgen, (b) Henri Becquerel.

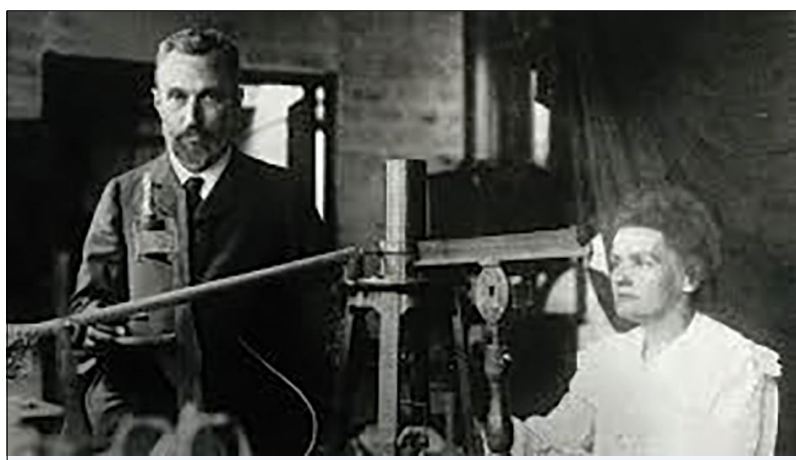

Fig. 2. Marie Sklodowska Curie and Pierre Curie.

Initially, radium sources were formed with superficial applicators. Henri Becquerel and Pierre Curie observed the biological effects of radium on the skin. In 1901, Marie and her husband Pierre Curie had loaned a small radium tube containing $0.398 \mathrm{~g}$ of radium sulfate to Alexandre Danlos and Paul Bloch at St. Louis Hospital in Paris, who treated a patient with lupus and then the treatment of malignant tumors by brachytherapy was started.[2]

Radium rays were soon found to have biological properties similar to those of X-rays. In 1903, Becquerel, together with Marie and Pierre Curie, received the Nobel Prize for Physics for their discovery of radioactivity. In the same year, the treatment of radium in gynecological malignancies was reported for the first time.

In 1903, the first gynecological brachytherapy was described by Margareth A. Cleaves in New York. Patient with inoperable cervix uteri cancer was treated with $700 \mathrm{mg}$ radium bromide put into the glass tube. [3] In New York, Robert Abbe from St. Luke Memorial Hospital performed the first radium implant following the excision of tumor in 1905. After removing the tu- mor, he placed radium capsules previously implanted in celluloid tubes into the tumor bed. Thus, he pioneered the afterloading technique of radium treatment in the United States.

On 19 April 1906, Pierre Curie died in a tragic street accident. His death was a turning point in both Marie's personal life and career, because she had to bring up her two daughters. However, she did not give up and continued their common work.

In 1906, Danne, Dominici, Degrais, and Wickham established the first "Radium Biological Laboratory" in Paris. In 1909, Finze started treating patients with radium in England. Treatment of prostatic disease with radium was first reported in Paris, at a meeting of the Assoçiation Françoise d'Urologie in October 1909.[4] Henri Minet treated cancers of the prostate, bladder, and ureter with a silver tube containing $10 \mathrm{mg}$ of radium, applied through a urethral catheter or a suprapubic cystotomy.[5]

Urologist Octave Pasteau and radium therapist Paul-Marie Degrais also began treating prostate cancer with intracavitary radium in 1909, but their first reports did not appear for several years.[6] Pasteau's rationale for preferring brachytherapy to prostatectomy was that "in cancer of the prostate the curative treatment by operation is in truth illusory; it is dangerous, and gives the most temporary results," whereas these tumors are "particularly susceptible to the influence of radium." [7]

They had used a silver capsule, containing 10 to $50 \mathrm{mg}$ of radium sulfate, placed near the tip of a $17 \mathrm{Fr}$ coudé urinary catheter. Five treatment sessions, each lasting 2 to 3 hours, were delivered over 2 weeks. The series could be repeated periodically (annual maintenance treatments were prescribed for patients who had enjoyed a complete response). The first radium therapy book was published by Wickham and Degrais in 1909 and was translated into English soon.[8]

In 1909, Marie founded the Institute of Radium in Paris, which was designed to study radioactivity and the biological effects of ionizing radiation. For that purpose, the Institute was divided into two laboratories: the Curie Pavilion, directed by Marie Curie, and the Pasteur Pavilion, directed by Claudius Regaud, a professor of histology and pathology.

After death of Pierre Curie, Marie Curie continued her research. The Nobel Prize in Chemistry 1911 was awarded to Marie Curie, "in recognition of her services to the advancement of chemistry by the discovery of the elements radium and polonium, by the isolation of radium and the study of the nature and compounds of this remarkable element." 
With the discovery of the radium isotope, clinical trials and experiments have increased rapidly. Curie is defined as the activity unit of a nuclear decay rate of $1 \mathrm{~g}$ radium. After 1950s, the dose calculations of the obtained radioisotopes and the dose calculations in the brachytherapy applications were based on the mg-radium equivalent (mgRaEq).

Although pitchblende ore is almost 50\% uranium, radium makes up only about one part per million. Tons of uranium ore were processed to obtain a single gram of radium. James Douglas, a Canadian-American mining engineer, and surgeon Howard Kelly (America's leading gynecologist) established the "National Radium Institute" in cooperation with the Office of the United States Bureau in 1913. A total of 8.5 grams of radium were refined until 1917. One-half gram was donated to government hospitals, and the remaining radium was divided between Kelly and Douglas. Douglas donated his $4 \mathrm{~g}$ to New York's Memorial Hospital, with the stipulation that the hospital become dedicated to the treatment of cancer.[9]

Radium's specific activity (ratio of activity to mass) is low, due to its long half-life (1.600 years). In practical terms, it takes at least a week to deliver a curative dose with radium needles. This would be particularly awkward for the treatment of prostate cancer, as the sources would be left in an open suprapubic or perineal wound for an extended period.[10] The solution to this problem lies in radon, radium's first daughter product. Radon has a very high specific activity, owing to its short (3.8 day) half-life; despite being a gas, $1 \mathrm{Ci}$ of radon has a volume of less than $1 \mathrm{~mm}^{3}$. Because of its high specific activity, an "emanation" needle could be much thinner than a radium needle. Consequently, radium salts were kept in an aqueous solution, and the emitted radon gas was harvested for therapeutic applications. Unfortunately, the collected gas was mostly composed of water vapor, hydrogen, and oxygen. Harvard biophysicist William Duane had spent 7 years as a research associate of the Curies, much of that time focusing on the purification of radon. On his return to the United States, he built a radium emanation plant at Boston's Collis P. Huntington Hospital, which he replicated at Memorial Hospital.[11,12]

Memorial's entire $4 \mathrm{~g}$ of radium was kept in solution, and the purified radon was encapsulated in short lengths of glass capillary tubes, $0.3 \mathrm{~mm}$ in diameters, which were inserted into hypodermic needles. The radon-bearing needles were used for temporary implantation (the needles' steel filtered most beta particles and soft gamma rays). A radium department was established at Memorial Hospital in 1915 with Henry H. Juneway, a surgeon. Beginning in 1915, Memorial's urologist, Benjamin Barringer, used these needles for outpatient treatment of prostate cancer.[13] The needle, bearing $50-100 \mathrm{mCi}$ of radon in its distal $3 \mathrm{~cm}$, was left in place for 4 to 6 hours before being retracted and inserted into the other lateral lobe. Barringer reported highly favorable tumor responses. At first, "bare" glass tubes were implanted into tumors, but this practice resulted in painful sloughing of necrotic tissue. Memorial's physicist, Gioacchino Failla, recognized the offender to be unfiltered caustic beta particles. He remedied the problem by encasing the radon in a $0.3-\mathrm{mm}$-thick envelope of gold that filtered out $99 \%$ of beta particles, while allowing $>80 \%$ of therapeutic gamma rays to pass. [14] Barringer implanted up to 20 seeds, each containing 1.5 to $2.0 \mathrm{mCi}$ of radon, into the prostate, typically delivering $4.000 \mathrm{mCi} \mathrm{h}$ of treatment.[15] Barringer's techniques were adopted at other institutions [16,17], and a "gold" radon seed industry was established, which persisted in the United States for decades.[18]

After the First World War, radium treatment of carcinoma of the cervix was started by Gösta Forssell in 1910 when Radiumhemmet (the Radium House) was established in Stockholm. In 1914, the radiotherapy department was divided into a gynecology section under James Heyman and a general section. The brachytherapy method for treatment of cervix carcinoma is usually referred to "the Stockholm technique" and the method for the treatment of uterus carcinoma as the "Heyman packing technique." At the same time, the Memorial Hospital in New York and Institut du Radium/Curie Institute in Paris were established. In these centers, dosimetry systems have been developed for two-dimensional (2D) dose distributions and point dose calculations before the computer age. Methods of intracavitary brachytherapy were described by the schools of Stockholm and Paris in 1914 and 1919, respectively. In the 1920s, Edith H. Quimby calculated the erythema-producing exposure dose in terms of "mg Ra h" at the New York. [19]

In the 1920, the interest and contributions to radiology increased; Sievert in Sweden, Mayneord in England and Dessauer in Germany established their laboratories. In the 1930s, the historical dosage systems were developed when computer treatment planning and dose computations were not available. The Quimby system by E. Quimby in New York and the PatersonParker calculation system by Ralston Paterson and Herbert Parker in Manchester were developed for in- 
tracavitary brachytherapy.[20-22] Paterson, Tod, and Meredith introduced two arbitrary points, A and B, to integrate $\mathrm{x}$-ray doses given from outside, with gamma doses administered internally. Then, the rules of interstitial radium treatment were published by Meredith as Manchester system.[23]

Ernest Rutherford's discovery of artificial radioactivity (a winner of the Nobel Prize in Chemistry in 1908) in 1919 became the source of significant breakthrough in diagnosis and treatment in physics and medicine. After the very first discoveries made by Ernest Rutherford, Pierre and Marie Curie's daughter, Irène Joliot-Curie, and her husband, Frédéric Joliot (Fig. 3), a new point of view was developed. They discovered that the point of view that although atoms appear to be stable, they can be transformed into new atoms with different chemical properties. In 1934, Irène Curie and Frederick Joliot discovered artificial radionuclides and opened the possibility of a new era of brachytherapy using artificial radionuclides.

Today, over one thousand artificially created radioactive nuclides exist, which considerably outnumber the non-radioactive ones created. The Nobel Prize in Chem-

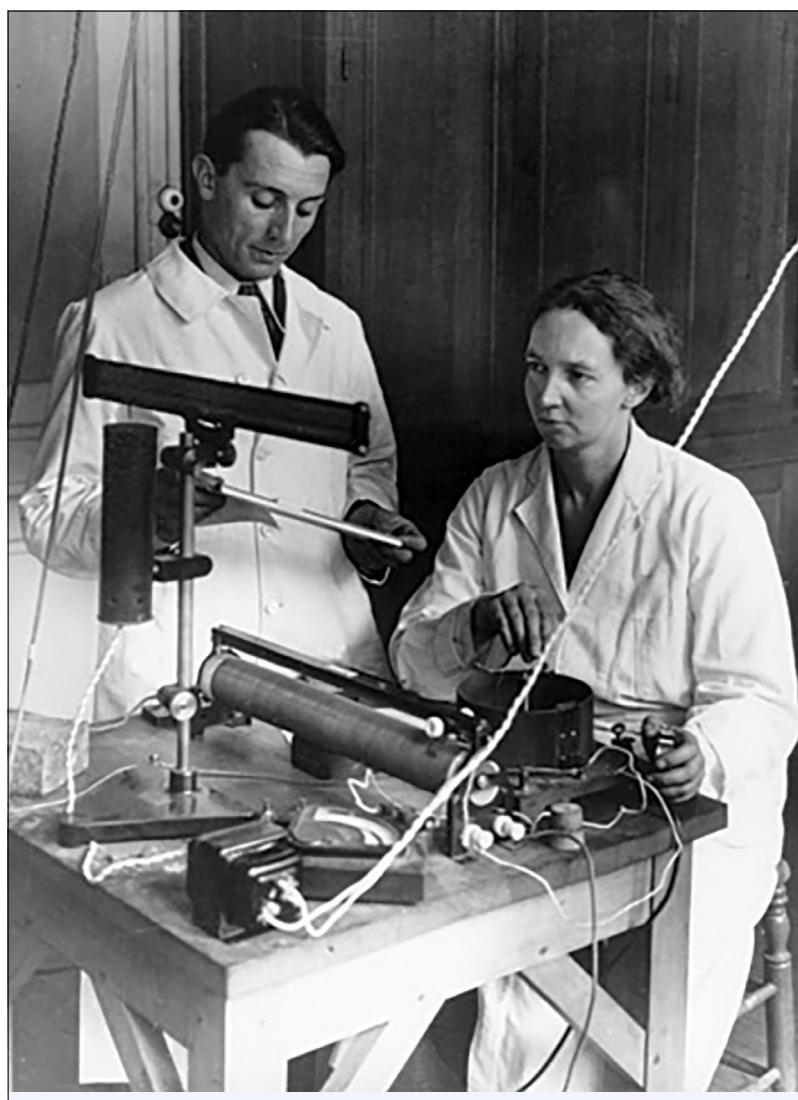

Fig. 3. Irene and Frederic Joliot-Curie. istry 1935 was awarded jointly to Frédéric Joliot and Irène Joliot-Curie "in recognition of their synthesis of new radioactive elements." In the decade after World War II, radioisotopes such as cobalt-60 (Co-60), gold-198 (Au198), tantalum-182 (Ta-182), and cesium-137(Cs-137) were introduced and became the radionuclides of choice in intracavitary therapy, replacing radium-226. In 1958, iridium-192 (Ir-192), which replaced these sources, was first used clinically by Ulrich Henschke at the Memorial Sloan Kettering Cancer Center.[24]

In 1960, Henschke described an afterloading technique for tumors of the uterus and cervix, which reduced exposure to staff. He inserted empty containers in the operating room and later in the ward inserted radioactive sources via connecting tubes.

In 1935, Prof. Dr. Friedrich Dessauer founded The Radiology and Biophysics Institute of Istanbul University (today's Istanbul University Oncology Institute) (Fig. 4), which was one of the most advanced institutes of the time with regard to technical equipment.

Brachytherapy had been started in Turkey with this Institute using radium needle and tubes. Dessauer had brought $100 \mathrm{mg}$ radium with him when coming to Turkey.[25] In a short time, the radium capacity was increased to $200 \mathrm{mg}$ for intracavitary and interstitial applications.

In 1952, The MD Anderson technique was presented by Gilbert Fletcher. The Fletcher applicator, which is the most widely used vaginal colpostate in the United States, was identified in 1953.[26]

Prof. Dr. Reha Uzel who worked with Ulrich Henschke and pioneered gynecological tumors and brachytherapy in Turkey was the first to perform the intracavitary application with Manchester type rubber ovoid and intrauterine applicators in 1955 with Seyfettin Kuter (the pioneer of medical physics in Turkey) (Fig. 5). He applied Au-198 seeds and Ta-182 hairpins to various tumors at Radiotherapy Department of Istanbul Medical Faculty. Figure 6 shows the brachytherapy applications in Radiology Institute, radiotherapy department in 1955.[27]

In 1957, eye tumors were treated with stronsiyum-90 (Sr-90) eye applicators. Applicators are currently used in the clinic.

The occupational concern related to the harmful effects of radium exposure in the second half of the $20^{\text {th }}$ century, technical advances in external beam treatment, advances in imaging and surgical methods have led to a decrease in the interest in brachytherapy and a significant decrease in its use. However, the discovery of manmade radioisotopes and remote afterloading techniques 

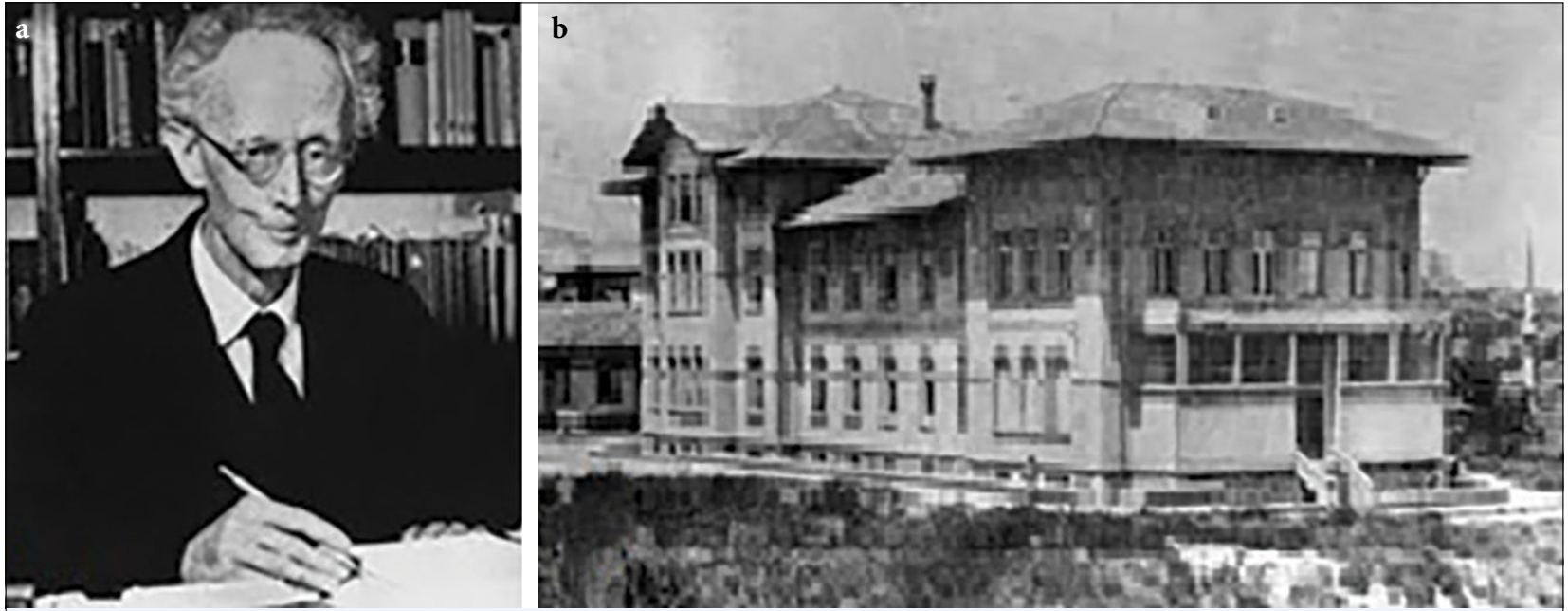

Fig. 4. (a)Prof. Dr. Friedrich Dessauer, German physicist, (b)The Radiology and Biophysics Institute, Çapa (1935).
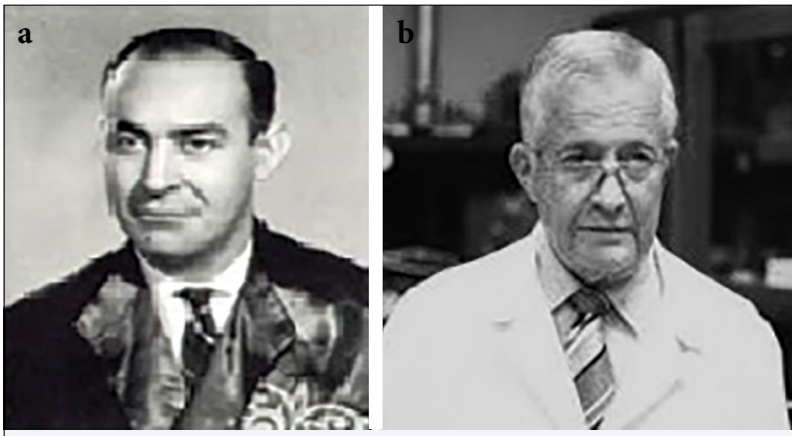

Fig. 5. (a) Prof. Dr. Reha Uzel, (b) Assoc. Prof. Dr. Seyfettin Kuter.

and subsequent reduction of the risk of exposure to radiation has renewed interest in brachytherapy.

In the 1960s, Drs Scardino and Carlton [28] at Baylor College of Medicine in Houston, TX, started to perform permanent prostate brachytherapy alone or with external beam radiation therapy using Au-198 interstitial implantation or iodine-125 (I-125).

In 1969, the Co-60 remote controlled Cathetron device was established at the radiotherapy department (Çapa) at Istanbul Faculty of Medicine. Thus, the highdose-rate (HDR) brachytherapy was started. In 1973, Dr. Gökhan Töre, a gynecologist, started working as an assistant at the same department and predominantly head toward to gynecological oncology.

Following the transfer of Dr. Uzel to Radiation Oncology of Cerrahpaşa Medical Faculty in 1978, he contributed greatly to the development of gynecological oncology and brachytherapy. In 1979, Curietron HDR Co-60 and low-dose-rate (LDR) Cs-137 brachytherapy devices were built in the Çapa and Cerrahpaşa Radiation Oncology department of Istanbul University. As a result of developing technologies, many HDR brachytherapy devices have been used especially in intracavitary brachytherapy.

In the 1970s, the dosimetry rules of the Paris system were determined by Chassagne, Pierquin, and Dutreix (Fig. 7) in interstitial treatment.[29-31]

By means of these rules, radioactive Ir-192 wires could be loaded to be manually afterloading to surgically implanted empty tubes by $2 \mathrm{D}$ imaging methods. In the 1980s, new brachytherapy approaches to the treatment of prostate cancer were initiated.[32] Martinez and colleagues [33] treated patients with EBRT combined with temporary seeds inserted using a transperineal approach. Dr Puthawala and colleagues [34] pioneered a temporary seed technique of placing the needles, while visualizing them through an open laparotomy. At about the same time, Dr Whitmore and colleagues [35] at Memorial Sloan Kettering Cancer Center also began to insert I-125 seeds as a sole treatment through an open incision. Significant limitations, such as the requirement for an open incision, dosimetry issues, and poor outcomes, prevented the adoption of these techniques. Lack of prostate-specific antigen screening (for ideal patient selection) also contributed to high recurrence rates. However, some important information was obtained from these early seed implantation approaches. Local control was better in patients who received high-quality implants and who had lowgrade and early-stage cancer.[36-38]

These results suggested that quality seed placement and proper patient selection were important determi- 

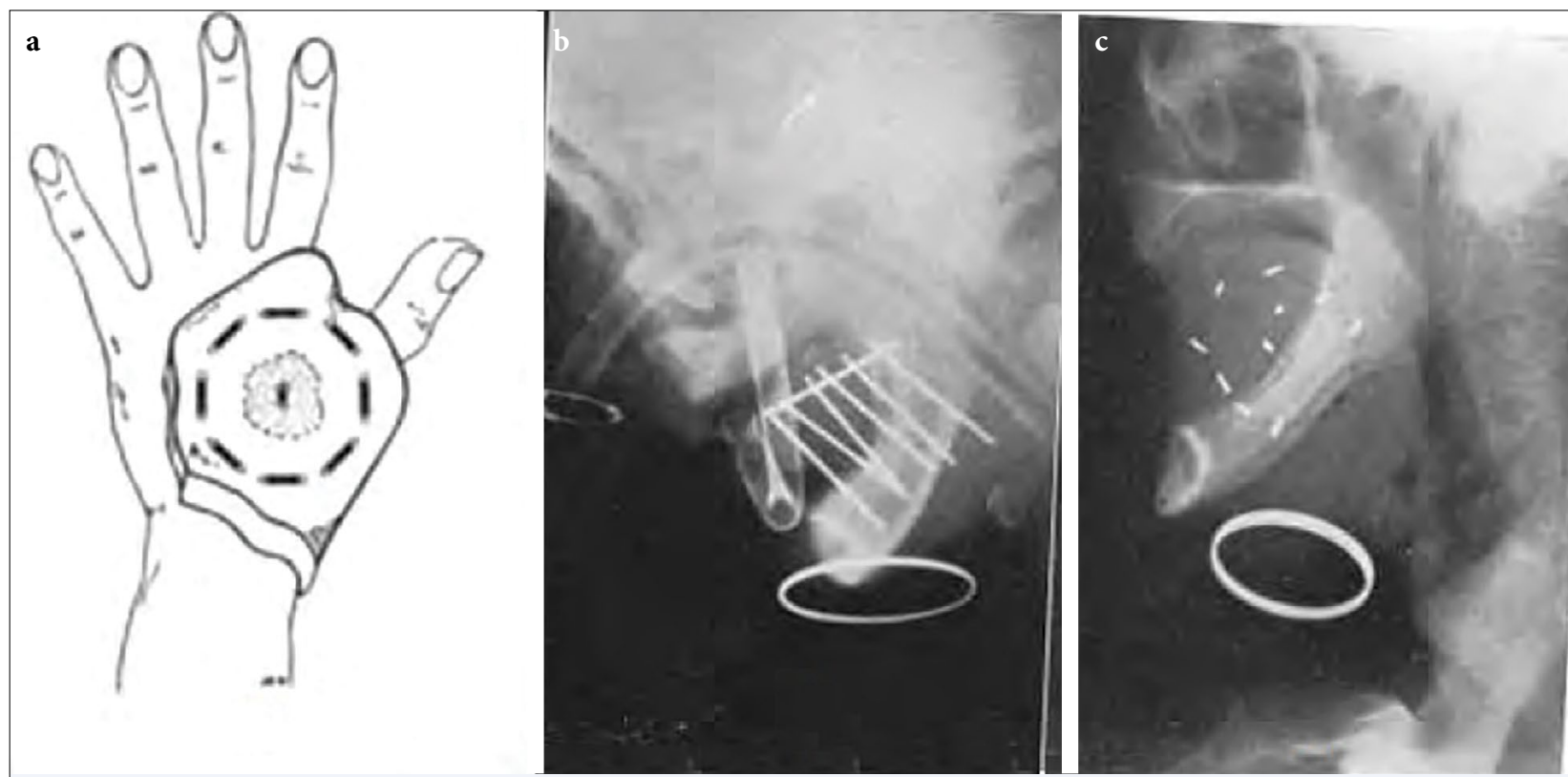

Fig. 6. (a) Surface treatment with Ra-226 tubes in cancer treatment, (b) interstitial brachytherapy with Ra-226 needles, (c) treatment with the Au-198 seeds.
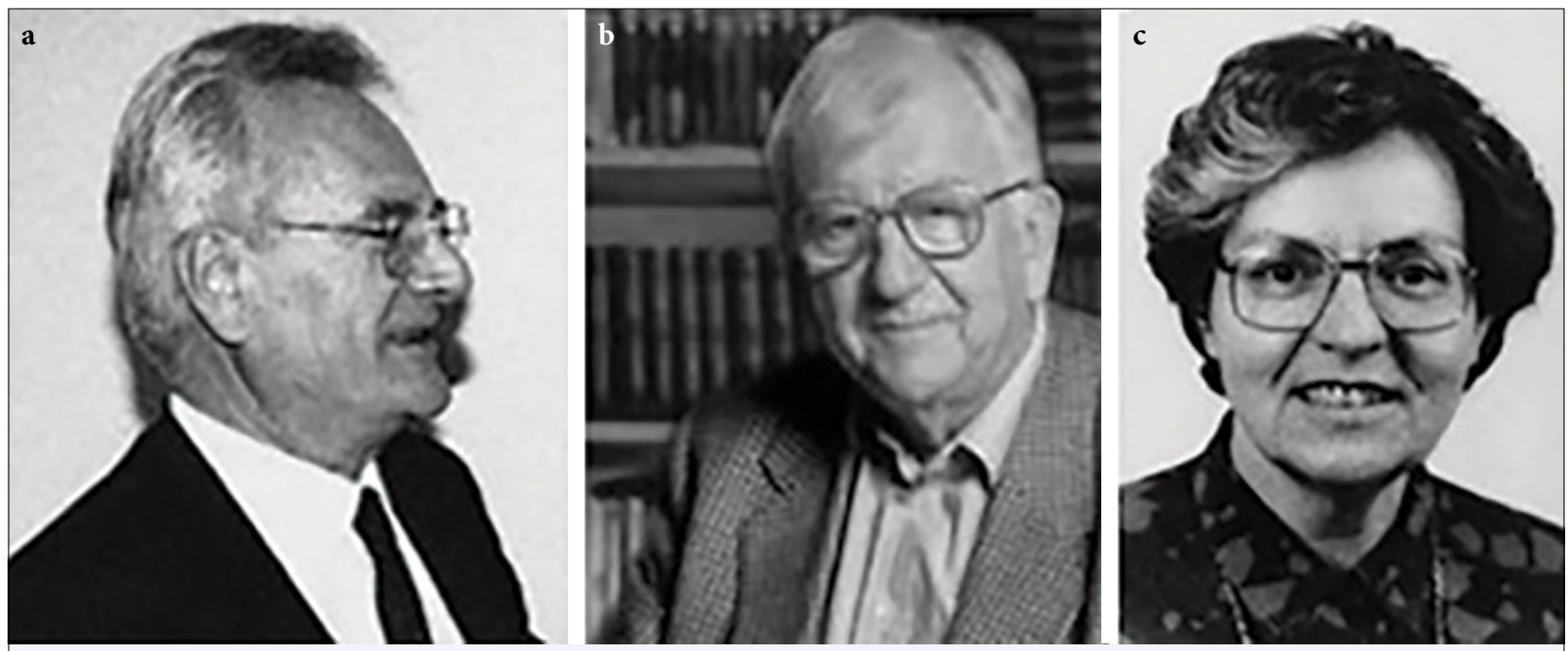

Fig. 7. (a) Daniel Chassagne, (b) Bernard Pierquin, (c) Andrée Dutreix.

nants of cancer control. The subsequent development of the transperineal, ultrasound-guided approach provided a theoretical means to more accurately place seeds and to improve dose coverage.

The use of low-energy photon sources such as I-125, Pd-103 and Cs-131 with permanent implant technique has been widely used in the treatment of prostate cancer since the 1980s. Since the mid-1980s, the transrectal ultrasound-guided, template-guided I-125 implantation procedure has become the primary technique of permanent seed implantation. In 1983, Hans Henrik Holm [39] introduced the use of transrectal ultrasound to visualize the permanent placement of I- 125 seeds via needles inserted through the perineum directly into the prostate. He was implanting I- 125 seeds into cancerous prostates, under the direction of axial imaging from a rectal probe mounted on a sledge-stepper (stepping unit). Preplanning and implantation were performed with the patient in the lithotomy position. In 1985, Blasko and Ragde [40] began the first transperineal, 

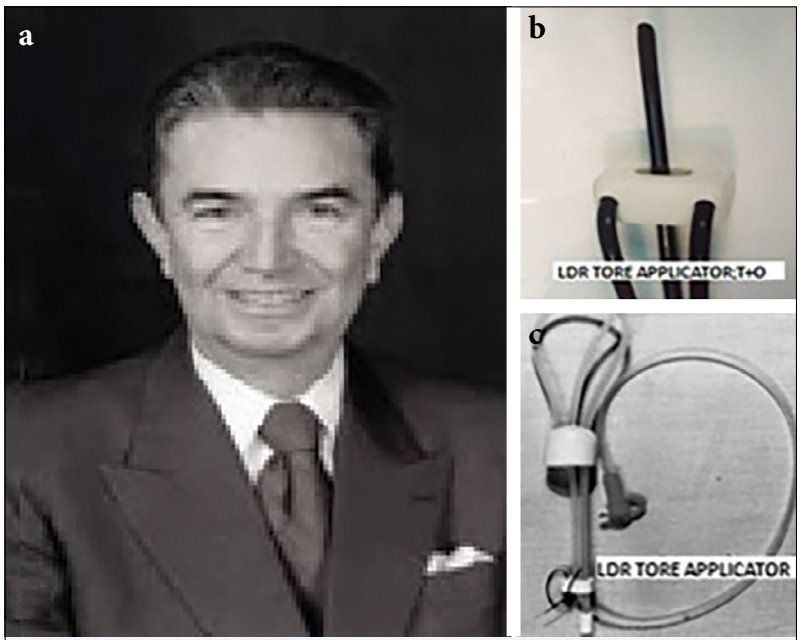

Fig. 8. (a) Prof. Dr. Gökhan Töre, (b) T+O applicator for uterus and cervix, (c) ans applicator for vaginal vault.

ultrasound-guided approach in the United States. The transperineal, ultrasound-guided approach resulted in increased accuracy of needle and seed placement and relatively even distribution of seeds throughout the prostate. It marked a major advance in prostate brachytherapy that it allowed computerized treatment planning of the implant rather than the use of simple nomograms, thus ensuring the proper number, strength, and positioning of radioactive sources. Permanent seed implantation has subsequently evolved over the past 19 years to become an efficient procedure, suitable for outpatient and ambulatory surgical centers.

In the 1990s, interstitial applications were started with low-dose Ir-192 wires in the Department of Radiotherapy (Çapa) in the Istanbul Medical Faculty of Istanbul University. With the introduction of Ir-192 into brachytherapy, radium sources have been replaced by this new source for intracavitary and interstitial therapy. The LDR intracavitary afterloading applications were continued with tandem ovoid applicator and an applicator developed by Töre [41] for the cervix and vaginal vault irradiation (Fig. 8).

Since 2000, permanent prostate brachytherapy (Fig. 9) has been performed under the guidance of transperineal ultrasound with LDR I-125 sources at the Oncology Institute of Istanbul. At the same time, plaque brachytherapy (Fig. 10) was initiated with I-125 sources for the treatment of uveal melanoma.
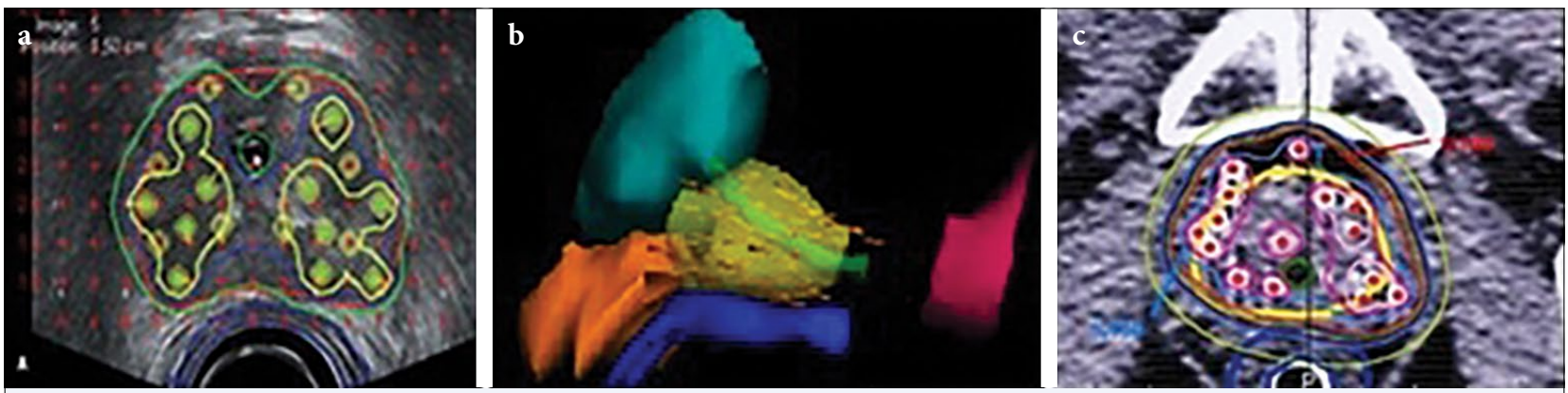

Fig. 9. Permanent prostate brachytherapy with LDR I-125 sources.
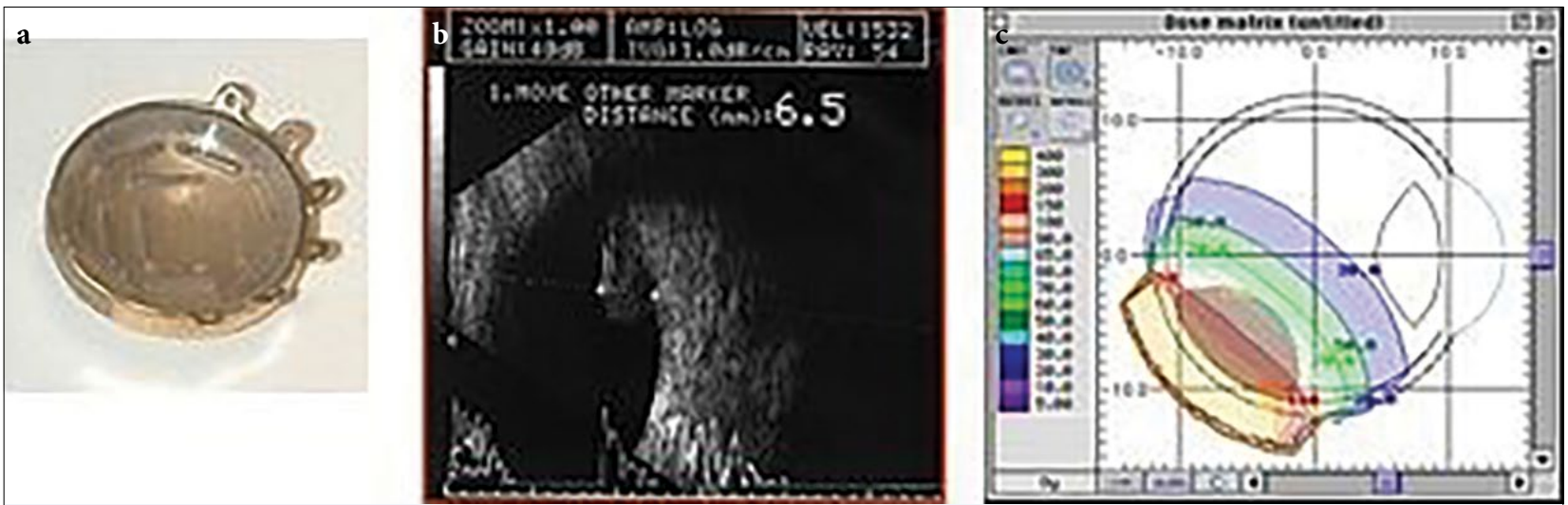

Fig. 10. Plaque brachytherapy with I-125 sources for the treatment of uveal melanoma. 
In brachytherapy, the traditional approach based on two orthogonal radiographs taken after placement of applicators has a limited treatment planning optimization capability. The optimization of cervical cancer brachytherapy is aimed at providing an adequate dose to Manchester A point by keeping the doses at the ICRU rectum and bladder points below the dose limits.[42]

Later, remote afterloading devices were further developed with the programable miniature high activity moving source (stepping source). HDR treatments and pulsed-dose-rate (PDR) treatments replaced LDR brachytherapy, except for LDR prostate permanent brachytherapy and uveal melanoma brachytherapy. Newer imaging modalities [computed tomography (CT) scan, magnetic resonance imaging (MRI), transrectal ultrasound] and sophisticated computerized treatment planning has helped to achieve increased positional accuracy and superior, optimized dose distribution.

The local control rates of traditional brachytherapy are approximately $80 \%-90 \%$ for small tumors, whereas the results for local advanced disease are suboptimal.[43] Cross-sectional imaging has been implemented in the brachytherapy planning in many centers over the last decade. Optimization has been the standard feature of brachytherapy systems by changing the dwell time. 3D image-guided adaptive brachytherapy provides a comprehensive assessment of tumor size in the diagnosis and each brachytherapy fraction. GYN GEC ESTRO Working Group published reports on volume concepts.[44,45] At present, MRI is preferred for the clinical and radiological primary tumor spread in brachytherapy and the understanding of the topography during brachytherapy. Compared with traditional brachytherapy, the dosimetric advantages of this approach have increased uncomplicated cure rates.[46,47] In contrast to limited 2D brachytherapy applications in well-defined geometric settings (gynecology, breast, and skin), advances in imaging techniques, increased knowledge of radiation administration, and dosimetry have made possible the $3 \mathrm{D}$ treatment of complex tumor sites. The development of HDR and the use of MR devices and the inclusion of PET-CTs have brought new dimensions to brachytherapy. After the superiority of MRI in determining the tumor volume in brachytherapy was demonstrated, MR-compatible applicators have been widely used in clinics.

Brachytherapy, because of its features such as individuality, conformity to tumor, and anatomical struc- ture and protection of surrounding tissues from high doses is a conformal treatment modality. As a result of technical developments in imaging and computer software, IMRT (inverse planning) and adaptive planning techniques can be used in brachytherapy as in external radiotherapy. Even in curative treatment of cervical cancer, adaptive therapies have become a necessity in some settlements. With the publication of ICRU 89, these treatments have been standardized worldwide. [48] Most of the devices in our country were established in the 2000s. [49] With the development of empirical $2 \mathrm{D}$ therapies and the development of software technology from the beginning to the present, brachytherapy has evolved into 3D treatments and continues to undergo a change reflecting today's technology. In a number of radiotherapy centers, brachytherapy treatment volumes can be determined in $3 \mathrm{D}$ by CT, MR, PET, or ultrasound. It is expected that it is the wide introduction of modern imaging tools into the clinical practice. New generation dose calculation algorithms supply the tissue inhomogeneity corrections in planning systems. With inverse planning, as with IMRT, dose optimization becomes the standard in CT treatment planning for many anatomical regions. Nevertheless, it is necessary to know that optimization cannot make a good dose distribution from a bad implant. In all treatments, radiobiological factors should be considered in combination of external radiotherapy and brachytherapy. Therefore, routine use of biological optimization in brachytherapy is one of the ongoing studies. Joint databases for MC-based algorithms will form the backbone of the new generation of commercial treatment planning systems, in a combination with a new validation prerequisite for those new algorithms. Dose-to-water standards for brachytherapy source calibration become available with a better or at least similar uncertainty level.

As a result, brachytherapy, with its 120-yearslong history, preserved its importance. It is clear that brachytherapy is the optimal way of delivering conformal radiotherapy tailored to the shape of the tumor, while sparing the surrounding normal tissue. With the development of application techniques and technology, its effectiveness increased further. Today, with the development of imaging techniques, individual dose planning has become possible with the development of CT and MRI. The success of brachytherapy has increased with extensive technological advances and ultimately the ability to produce very accurate $3 \mathrm{D}$ radiation dose distributions in the patient and optimization of brachytherapy planning. 


\section{References}

1. Brucer M. Brachytherapy. Am J Roentgenol Radium Ther Nucl Med 1958;79(6):1080-90.

2. Pierquin, B., Wilson, J.F., Chassagne, D. Modern brachytherapy. NY: Masson Publishing USA; 1987. p. $25-42$.

3. Aronowitz JN, Aronowitz SV, Robison RF. Classics in brachytherapy: Margaret Cleaves introduces gynecologic brachytherapy. Brachytherapy 2007;6(4):293-7.

4. Aronowitz JN, Grimard DL, Robison R. Precedence for prostate brachytherapy. Brachytherapy 2011;10(3):201-7.

5. Minet $\mathrm{H}$. Applications du radium aux tumeurs vesicales, a l'hypertrophie et au cancer de la prostate, etc [Applications of radium to bladder tumors, prostatic hypertrophy and cancer, etc.]. Proc Verb Mem Assoc Franc Urol 1909;13:629-46.

6. Pasteau O, Degrais. De l'emploi du radium dans le traitement des cancers de la prostate [The employment of radium in the treatment of prostate cancer]. J Urologie Med Chirur 1913;4:341-66.

7. Pasteau O, Degrais. The radium treatment of cancer of the prostate. Arch Roentgen Ray 1914;18:396-410.

8. Wickham L, Degrais P. Radiumtherapie. Bailliere. Paris; 1909.

9. Aronowitz JN, Robison R F. Howard Kelly establishes gynecologic brachytherapy in the United States. Brachytherapy 2010;9(2):178-184.

10. Cade S. Radium Treatment of Cancer. New York, NY: William Wood; 1929.

11. Failla G. The physics of radium. In: Clark JG, Norris CC, editors. Radium in Gynecology Philadelphia, PA: JB Lippincott; 1927. p. 63.

12. Duane W. Methods of preparing and using radioactive substances in the treatment of malignant disease and of estimating suitable doses. Boston Med J 1917;177:787-99.

13. Barringer BS. The treatment by radium of carcinoma of the prostate and bladder. JAMA 1916;67:1442-5.

14. Failla G. The development of filtered radon implants. Am J Roentgenol Radium Ther 1926;16:507-25.

15. Barringer BS. Treatment of tumors of the urinary bladder and prostate gland. In: Portmann UV, ed. Clinical Therapeutic Radiology. New York, NY: Thomas Nelson \& Sons; 1950. p. 309-22.

16. Bumpus HC. Carcinoma of the prostate: a clinical study of a thousand cases. Surg Gynecol Obstet. 1926;43:150-5.

17. Watson EM. A study of carcinoma of the lower urinary tract. J Urologie Med Chirur 1933;29:545-57.

18. Lubenau JO. Unwanted radioactive sources in the public domain: a historical perspective. Health Phys 1999; 76(2 Suppl): S16-S22.
19. Quimby EH. The development of dosimetry in radium therapy. In: Hilaris BS, ed. Afterloading: 20 years of experience, 1955-1975. Proceedings of the 2nd International Symposium on Radiation Therapy. New York: Memorial Sloan-Kettering Cancer Center; 1975. p. 1-6.

20. Quimby EH. The grouping of radium tubes in packs and plaques to produce the desired distribution of radiation. Am J Roentgenol and Rad. Ther 1932;27:18-39.

21. Paterson $\mathrm{R}$, Parker $\mathrm{H}$. A dosage system for gamma ray therapy. 1934. Br J Radiol 1934;7(82):592-632.

22. Paterson R, Parker HM. A dosage system for interstitial radium therapy. Br J Radiol 1938;11(124):252-66.

23. Meredith WJ. Radium dosage: Manchester system. 2nd ed. Edinburg: Livingstone; 1967.

24. Henschke UK, Hilarıs BS, Mahan GD. Afterloading in interstitial and Intracavitary radiation therapy. Am J Roentgenol Radium Ther Nucl Med 1963;90(8):386-95.

25. Berkman AT. Engelli-engebeli uzun yıllar [In Turkish] [Long years of difficulties and obstructions]. Istanbul: Selar Ofset 1987;174:153-4.

26. Fletcher GH. Cervical radium applicators with screening in the direction of bladder and rectum. Radiology 1953;60(1):77-84.

27.26. Kuter S. Türkiyede radyoloji biliminin kuruluş tarihi. Türk Onkoloji Dergisi 2011;26 Ek 1:1-74.

28. Scardino P, Carlton C. Combined interstitial and external irradiation for prostatic cancer. In: Javadpour $\mathrm{N}$, editor. Principles and Management of Urologic Cancer. Baltimore, MD: Williams \& Wilkins; 1983. p. 392-408.

29. Chassagne D, Raynal M, Pierquin B. Technic of endocurietherapy by iridium 192 with plastic tubes in the breast tumors. [Article in French]. J Radiol Electrol Med Nucl 1963;44:269-71.

30. Pierquin B, Chassagne D, Chahbazian CM, Wilson JF. Brachytherapy. W.H. Green, editor. St Louis, Missouri; 1978.

31. Dutreix A, Marinello G, Pierquin B, Chassagne D, Houlard JP. Recent developments in the Paris System. Part two: devices called "in triangles" (author's transl). [Article in French]. J Radiol 1979;60(5):319-25.

32. Sylvester J, Blasko JC, Grimm P, Ragde H. Interstitial implantation techniques in prostate cancer. J Surg Oncol 1997;66(1):65-75.

33. Martinez A, Edmundson GK, Cox RS, Gunderson LL, Howes AE. Combination of external beam irradiation and multiple-site perineal applicator (MUPIT) for treatment of locally advanced or recurrent prostatic, anorectal, and gynecologic malignancies. Int J Radiat Oncol Biol Phys 1985;11(2):391-8.

34. Puthawala A, Syed A, Tansey L. Temporary iridium implant in the management of carcinoma of the prostate. Endocurie Hyper Oncol 1985;1:25-33. 
35. Whitmore WF Jr, Hilaris B, Grabstald H. Retropubic implantation to iodine 125 in the treatment of prostatic cancer. J Urol 1972;108(6):918-20.

36. DeLaney TF, Shipley WU, O'Leary MP, Biggs PJ, Prout GR Jr. Preoperative irradiation, lymphadenectomy, and 125iodine implantation for patients with localized carcinoma of the prostate. Int J Radiat Oncol Biol Phys 1986;12(10):1779-85.

37. Fuks Z, Leibel SA, Wallner KE, Begg CB, Fair WR, Anderson LL, et al. The effect of local control on metastatic dissemination in carcinoma of the prostate: long-term results in patients treated with $125 \mathrm{I}$ implantation. Int J Radiat Oncol Biol Phys 1991;21(3):537-47.

38. Kovács G, Galalae R, Loch T, Bertermann H, Kohr P, Schneider R, et al. Prostate preservation by combined external beam and HDR brachytherapy in nodal negative prostate cancer. Strahlenther Onkol 1999;175 Suppl 2:87-8.

39. Holm HH, Juul N, Pedersen JF, Hansen H, Strøyer I. Transperineal 125iodine seed implantation in prostatic cancer guided by transrectal ultrasonography. J Urol 1983;130(2):283-6.

40. Blasko JC, Radge H, Schumacher D. Transperineal percutaneous iodine-125 implantation for prostatic carcinoma using transrectal ultrasound and template guidance. Endocurie Hyper Oncol 1987;3:131-9.

41. Töre G, Aslay I, Dinçer M, Kemikler G. A new iridium applicator for vaginal vault irradiation. Eur J Gynaecol Oncol 1994;15(3):241-4.

42. D. Chassagne A. Dutreix P. Almond J. M. V. Burgers M. Busch C. A. Joslin. International Commission on Radiation Units and Measurements (ICRU). Dose and volume specification for reporting intracavitary therapy in gynecology. ICRU Report 38. ICRU, Bethesda, MD; 1985.

43. Gerbaulet A, Pötter R, Haie-Meder C. Cervix cancer. In: Gerbaulet A, Pötter R, Mazeron JJ, Meertens H,
Van Limbergen E, eds. The GEC ESTRO Handbook of Brachytherapy. European Society of Therapeutic Radiology and Oncology, Brussels; 2002:300-63.

44. Haie-Meder C, Pötter R, Van Limbergen E, Briot E, De Brabandere M, Dimopoulos J, et al; Gynaecological (GYN) GEC-ESTRO Working Group. Recommendations from Gynaecological (GYN) GEC-ESTRO Working Group (I): concepts and terms in 3D image based 3D treatment planning in cervix cancer brachytherapy with emphasis on MRI assessment of GTV and CTV. Radiother Oncol 2005;74(3):235-45.

45. Pötter R, Haie-Meder C, Van Limbergen E, Barillot I, De Brabandere M, Dimopoulos J, et al; GEC ESTRO Working Group. Recommendations from gynaecological (GYN) GEC ESTRO working group (II): concepts and terms in 3D image-based treatment planning in cervix cancer brachytherapy-3D dose volume parameters and aspects of 3D image-based anatomy, radiation physics, radiobiology. Radiother Oncol 2006;78(1):6777.

46. Lindegaard JC, Tanderup K, Nielsen SK, Haack S, Gelineck J. MRI-guided 3D optimization significantly improves DVH parameters of pulsed-dose-rate brachytherapy in locally advanced cervical cancer. Int J Radiat Oncol Biol Phys 2008;71(3):756-64.

47. Pötter R, Georg P, Dimopoulos JC, Grimm M, Berger $\mathrm{D}$, Nesvacil N, et al. Clinical outcome of protocol based image (MRI) guided adaptive brachytherapy combined with 3D conformal radiotherapy with or without chemotherapy in patients with locally advanced cervical cancer. Radiother Oncol 2011;100(1):116-23.

48. Prescribing, Recording, and Reporting Brachytherapy for Cancer of the Cervix. J ICRU 2013;13(1-2):NP.

49. Kuter S, Çakır A. Survey of Radiation Oncology Centers, Equipment and Manpower. Türk Onkoloji Dergisi 2004;19(3):87-96. 